\title{
Effect of a Multicomponent Intervention Program on Community-Dwelling People With Intellectual Disabilities
}

\author{
Ye-Soon Kim, $\mathrm{PhD}^{1}$, Jong-Hoon Moon, $\mathrm{MS}^{1}$, Bo Kyoon Hong, $\mathrm{MS}^{2}$, Seung Hee Ho, $\mathrm{PhD}^{1}$ \\ ${ }^{1}$ Department of Healthcare and Public Health Research, National Rehabilitation Research Institute, \\ National Rehabilitation Center, Seoul; \\ ${ }^{2}$ Department of Occupational Therapy, Graduate School, Yonsei University, Wonju, Korea
}

\begin{abstract}
Objective To investigate the effectiveness of a novel and complex intervention in community-dwelling people with intellectual disabilities.

Methods Forty-three participants completed the experiment. The subjects were randomly assigned the experimental ( $\mathrm{n}=33)$ or control $(\mathrm{n}=10)$ groups. The multicomponent intervention program comprised exercise and nutrition management and behavior modification. The intervention was performed for 60 minutes once weekly for 10 weeks. The assessment included anthropometric data, body composition and blood pressure analysis, and blood tests. In addition, pulmonary function, physical function, and health-related quality of life were measured before and after the intervention.

Results No adverse events occurred during the intervention. After the intervention, the experimental group showed a significantly higher increase in high-density lipoprotein cholesterol level than did the control group (effect size $=0.152, \mathrm{p}=0.019$ ).

Conclusion This innovative intervention was effective in improving cardiovascular health. Even greater effects could be achieved through improvements in implementation strategies to increase compliance.
\end{abstract}

Keywords Community health services, Exercise, Health promotion, Intellectual disability, Obesity

\section{INTRODUCTION}

People with disabilities are more susceptible to overweight or obesity compared to people without disabilities.
According to the 2003-2008 US Centers for Disease Control and Prevention, the obesity rate among people with disabilities was $36 \%$, much higher than the $23 \%$ in people without disabilities [1]. In Korea, the prevalence of obesity

Received August 14, 2019; Revised October 18, 2019; Accepted January 3, 2020; Published online July 28, 2020

Corresponding author: Seung Hee Ho

Department of Healthcare and Public Health Research, National Rehabilitation Research Institute, National Rehabilitation Center, 58 Samgaksan-ro, Gangbuk-gu, Seoul 01022, Korea. Tel: +82-2-901-1921, Fax: +82-2-901-1930, E-mail: hsh7@korea.kr

ORCID: Ye-Soon Kim (https://orcid.org/0000-0003-1424-0163); Jong-Hoon Moon (https://orcid.org/0000-0002-2799-1823); Bo Kyoon Hong (https:// orcid.org/0000-0002-8806-2358); Seung Hee Ho (https://orcid.org/0000-0002-5208-1573).

(c) This is an open-access article distributed under the terms of the Creative Commons Attribution Non-Commercial License (http://creativecommons.org/ licenses/by-nc/4.0) which permits unrestricted noncommercial use, distribution, and reproduction in any medium, provided the original work is properly cited. Copyright (C) 2020 by Korean Academy of Rehabilitation Medicine 
was $41.6 \%$ among disabled people who underwent the nationwide health examination conducted by the National Health Insurance Service in 2015, 7.5\% higher than the national average obesity rate of $34.1 \%$ [2]. In particular, extreme obesity has become prominent amid continuously rising obesity in people with disabilities [2-5].

Obesity rates tend to increase among people suffering from mental health problems such as intellectual disabilities (ID) and autism [6,7]. A high prevalence of obesity reportedly poses a barrier to health promotion because outdoor activities become physically uncomfortable to perform. Furthermore, physical limitations and a lack of expressive skills may dampen their desire, although their intention to increase physical activity remains unchanged [8]. Imprudent eating habits are also cited as one of the major causes of obesity in people with ID [9].

The negative health effects of overweight or obesity are well established. A high body fat percentage causes various health problems such as joint burden while walking, in addition to an increased risk of coronary artery disease and type 2 diabetes [10]. Overweight or obesity may also cause mental health problems by negatively affecting confidence and self-efficacy and by triggering negative body image, stress, and depression [11].

Various solutions, including physical activity and nutrition, have been suggested to tackle obesity and improve health $[7,8]$. Physical activity is a composite term referring to all bodily movements needed to promote physical, cognitive, and emotional development using motor skills learned through maturation, growth, and experiences and to improve fundamental motor, perceptualmotor, and expressive skills. It is also defined as "bodily movement produced by skeletal a muscle that requires energy expenditure". The high rates of obesity in disabled people can reportedly be curbed through participation in physical activities [12].

Although the benefits of increased physical activity are well known in terms of health maintenance and obesity prevention, participation among disabled people remains low [13]. Nutritional management is also key to the treatment of obesity. In general, reducing caloric intake can lead to weight change. However, dietary control needs to be combined with exercise for obese older adults given their low metabolic rate and reduced mobility. A lack of nutrition or exercise can make weight management on a continuous basis difficult [14].
To date, studies on the health management of disabled people have focused on physical activity [15], exercise programs [16], nutrition health promotion interventions [17], psychological therapies [18,19], parental stress and quality of life [20], and behavior modification [21]. However, to our knowledge, investigations into the effects of multicomponent intervention programs (MIP) have been lacking [13-21]. The present study, therefore, aimed to assess the effects of participation in a 10-week MIP developed for people with ID that encompassed physical activity, obesity management, and behavior modification.

\section{MATERIALS AND METHODS}

\section{Design}

The present two-group pretest-posttest trial was followed by blinded analysis. This study was approved by the National Rehabilitation Institute Clinical Research Review Committee (No. NRC-2015-03-019).

\section{Participants}

The 50 people with ID who participated in this study were recruited through advertisements on welfare centers for the people with disabilities and the websites of ID communities. The inclusion criteria were as follows: aged 13 years or older, the Ministry of Health \& Welfare registered as people with ID as of January 1, 2015, and who understood the study objectives and agreed to participate. The exclusion criteria included serious conditions such as cardiovascular disease or orthopedic disorder affecting the ability to walk/exercise and participation in other health-related programs over the last 6 months. ID was graded from 1 to 3 according to the criteria of the Ministry of Health and Welfare. Level I was defined as those with an intelligence quotient (IQ) of less than 35 who required protection during their lifetime due to difficulty in adjusting their daily and social life. Level 2 was defined as people with an IQ of 35 and above but less than 50 who could be trained to perform simple behaviors in everyday life and, with some supervision and assistance, could have a job that was not complicated and did not require special skills. Level 3 ID was defined as people with an IQ of 50 or above and 70 or below who were capable of social and professional rehabilitation through education. Participants with ID levels 1 and 2 were accompanied by a caregiver when participating in 
the program. After briefing the parents of the participants and people with ID on the experimental plans and procedures, we collected informed consent from those who understood the study objectives and voluntarily agreed to participate in the study. All parents or legal guardians provided written informed consent before participation. The first author performed a sample size calculation (G*Power 3.1, http://www.gpower.hhu.de/). After setting alpha $=0.05$ and beta $=0.95$, the effect sizes were calculated. The results indicated that 50 subjects were required. People who participated in less than $90 \%$ of the MIP and those who were unable to perform follow-up tests were also excluded from the final analyses.

\section{Study procedure}

Of 50 potentially suitable participants, three were excluded as they failed to meet the inclusion criteria. The remaining 47 participants were randomly divided into the experimental $(n=37)$ or control $(n=10)$ groups in a 3:1 ratio [22]. Randomization was performed using Random Sequence Generator (https://www.random.org/ sequences/). After completing a baseline assessment, the experimental group underwent the MIP developed for this study, while the control group received no intervention. The control group received usual care and routine daily activities. The intervention program was performed at the welfare center at an intermediate point, based on its convenience and accessibility to the participants. During the 10-week intervention, four participants from the experimental group dropped out of the study. No participants from the control group dropped out of the study. Thus, the post-intervention assessment included 33 participants in the experimental group and 10 participants in the control group. The experiments were followed by blinded statistical analysis.

\section{Multi-intervention program}

This intervention program, focused on promoting physical, mental, and psychological health, was based on a study by Heller and Sorensen [23] that addressed health promotion in adults with ID through collaboration with related experts such as rehabilitation physicians, psychiatrists, clinical nutritionists, and physical trainers in special schools. The MIP was an intervention program that includes exercise, nutrition education, and behavior modification. The exercise component is a combination exercise program that combines five elements: stretch exercise, running or walking, aerobic exercise, strength exercise, and recreation. The nutrition education component was conducted on an hourly basis through preresearch and diet diary. The behavior correction program aimed to promote healthcare through phone and SMS as part of e-healthcare. The MIP comprised a total of 10 hours, conducted as 1-hour weekly sessions for 10 weeks and comprised 8 exercises and 2 nutritional sessions. This program was further revised and refined to be more applicable to the Korean context. The design of the MIP was geared toward increasing physical activity levels with the ultimate goal of improving self-management skills and quality of life. The components of the program are presented in Table 1.

\section{Outcome measures}

The testers performed anthropometric tests, body composition tests, blood pressure analysis, and blood tests and measured pulmonary function, physical function, and health-related quality of life (HRQOL). The outcome assessment was conducted by nurses and therapists from other institutions.

The anthropometric test included height, weight, and waist-hip ratio. Participants' height and weight were measured using a height gauge (DS-102; DS Jenix Co. Lrd., Seoul, Korea). The measured values were used to calculate the body mass index (BMI). To determine the waist-hip ratio, waist and hip circumference measurements were taken [24] in a standing position with both arms stretched horizontally. The former was measured at the midpoint between the lowest rib and iliac crest using a measuring tape, and the latter was measured horizontally using the measuring tape at the most protruding point of the buttock.

Body composition was measured using a body composition analysis system (InBody S10; InBody Co. Ltd., Seoul, Korea). For accurate measurements, the participants were asked to fast for 2 hours before measurement. First, the participants were asked whether they were using a pacemaker and those without a pacemaker underwent measurement using electrodes placed on both hands (between thumb and middle finger) and feet (between the lateral malleolus and Achilles tendon) in a standing position with feet shoulder-width apart and both arms slightly raised away from the body. Body fat 
Table 1. Components of the multi-intervention program

\begin{tabular}{|c|c|c|}
\hline Item & Components & Description \\
\hline \multirow[t]{6}{*}{$\begin{array}{l}\text { Physical } \\
\text { activity }\end{array}$} & Warming up & $\begin{array}{l}\text { Light gymnastics } \\
\text { - Exercise to mobilize each area of the body } \\
\text { - Activity is induced through physical contact }\end{array}$ \\
\hline & $\begin{array}{l}\text { Individual } \\
\text { exercise }\end{array}$ & $\begin{array}{l}\text { Walking (muscular endurance exercise as part of aerobic exercise) } \\
\text { - Walking (forward, backward, side-to-side, and toe walking) }\end{array}$ \\
\hline & & $\begin{array}{l}\text { Muscle strength exercise (muscle strength exercise as part of anaerobic exercise) } \\
\text { - Rope skipping } \\
\text { - Basketball dribbling } \\
\text { - Football dribbling } \\
\text { - Barrier running, running with a gym ball } \\
\text { - Relay running } \\
\text { - Round running }\end{array}$ \\
\hline & & $\begin{array}{l}\text { Aerobic exercises (muscular endurance exercise as part of aerobic exercise) } \\
\text { - Exercise with elastic bands }\end{array}$ \\
\hline & $\begin{array}{l}\text { Group } \\
\text { exercises }\end{array}$ & $\begin{array}{l}\text { Games for small groups } \\
\text { - Recreational games designed for small groups of participants }\end{array}$ \\
\hline & Cool-down & $\begin{array}{l}\text { Light stretching } \\
\text { - Gymnastics exercise }\end{array}$ \\
\hline \multirow[t]{2}{*}{$\begin{array}{l}\text { Nutrition } \\
\text { intervention }\end{array}$} & 1st session & $\begin{array}{l}\text { - Purpose and necessity of nutrition intervention (nutrition management for } \\
\text { health by selecting healthier foods) } \\
\text { - Choosing a well-balanced diet (understanding the composition of foods and } \\
\text { becoming aware of the problems resulting from an unbalanced diet) } \\
\text { - Understanding the effects of an unbalanced diet (obesity and its implications } \\
\text { as a disease) } \\
\text { - Healthy habits (regular life patterns, exercise, and healthy diet) }\end{array}$ \\
\hline & 2nd session & $\begin{array}{l}\text { - Nutritional information of foods associated with obesity (recommended } \\
\left.\text { amounts of sodium, sugar, and fat and setting measurement criteri }{ }^{\mathrm{a}}\right) \\
\text { - Instructions regarding nutritional facts on packaged foods (how to read and } \\
\text { understand them) } \\
\text { - Information on changes in nutrition depending on cooking methods (under- } \\
\text { standing sodium, sugar, and fat contents in packaged foods) } \\
\text { - Instructions for meals (reducing sodium, sugar, and fat intake and emphasiz- } \\
\text { ing correct health information) }\end{array}$ \\
\hline \multirow[t]{2}{*}{$\begin{array}{l}\text { Behavioral } \\
\text { intervention } \\
\text { training }\end{array}$} & Telephone & $\begin{array}{l}\text { - Greetings } \\
\text { - Identifying health status and providing the necessary consultation } \\
\text { - Checking the implementation of the programs assigned for each week } \\
\text { - Adjusting individual daily schedules } \\
\text { - Identifying queries or complaints regarding the program } \\
\text { - Releasing program schedules and announcements } \\
\text { - Encouraging continuous participation in the program }\end{array}$ \\
\hline & SMS & $\begin{array}{l}\text { - Greetings } \\
\text { - Releasing program timeline, clothing for exercise, and other announcements } \\
\text { - Encouraging continuous participation in the program }\end{array}$ \\
\hline
\end{tabular}

mass, body fat percentage, soft lean mass, and fat-free mass were measured [25].

Blood pressure measurements and blood tests were performed. To measure blood pressure in a relaxed state, the participants were instructed to take an approximately 10-minute rest in a sitting position. An automatic monitor (CH-452; Citizen Systems Japan Co. Ltd., Tokyo, Japan) was positioned at the level of the heart and a cuff was placed on the right upper arm. The blood test measured total cholesterol, triglycerides, high-density lipo- 
protein (HDL) cholesterol, and low-density lipoprotein (LDL) cholesterol levels among cholesterol components following fasting for at least 8 hours using a testing device (COBAS 8000 c702; Roche Diagnostics, Mannheim, Germany) [26].

Pulmonary function was measured using a spirometer (FVC Kit; Clement-Clarke International Ltd., Harlow, England) [27]. For the measurement, the participants placed their lips tightly around a mouthpiece, held the spirometer with both hands to ensure its stability, and inhaled maximally at the tester's indication. Air was then exhaled in a single breath from the lungs. When there was no more volume of air exhaled over time or a plateau in exhaled volume was reached, a forced exhalation was made for at least 10 seconds and the measurement was completed according to the tester's instructions. Forced vital capacity and forced expiratory volume at one second were measured.

Physical functional capacity was measured in different ways. The 6-minute walk test was used to assess cardiopulmonary function by measuring heart rates after walking as fast as possible for 6 minutes [28]. Grip strength in both hands was measured in a sitting position with the arms raised to form a right angle at the elbow. Sex and age were entered into a dynamometer and the amount of force with which the dynamometer could be squeezed was measured in kilograms [29]. In the sit-to-stand test, the participants started from sitting in a chair without armrests with each hand placed on the opposite shoulder, rose to a full stand, and then sat back down again.
The number of repetitions completed in 30 seconds was counted [30].

HRQOL was measured using the EuroQol-5D (EQ5D), consisting of five domains: mobility, self-care, usual activities, pain/discomfort, and anxiety/depression, with each scored on a 3-point scale. The EQ-5D assesses HRQOL in a questionnaire survey or face-to-face interview. The results are presented as EQ-5D index scores calculated using a formula, in which a score of 1 indicates the highest HRQOL [31].

\section{Statistical analysis}

The collected data were analyzed using IBM SPSS 21.0 (IBM Corp., Armonk, NY, USA). Shapiro-Wilk tests were performed to confirm that the data were normally distributed. Comparisons of general characteristics and dependent variables between the two groups were analyzed by chi-square and independent t-tests. Paired t-tests were conducted to compare pre- and post-intervention effects. The independent variables were the groups and the covariate were sex, age, degree of disability, comorbidity, and baseline values using analysis of covariance (ANCOVA). The significance level was set to 0.05 .

\section{RESULTS}

\section{General characteristics}

No participants reported an adverse event during the 10-week intervention. The general characteristics of the participants are presented in Table 2. No significant

Table 2. General characteristics in participants

\begin{tabular}{|c|c|c|c|}
\hline Characteristic & Experimental group $(n=33)$ & Control group $(n=10)$ & p-value \\
\hline Age (yr) & $26.52 \pm 5.32$ & $22.60 \pm 1.78$ & $0.029^{*}$ \\
\hline Gender & & & 0.131 \\
\hline Male & $22(66.7)$ & $4(40.0)$ & \\
\hline Female & $11(33.3)$ & $6(60.0)$ & \\
\hline Degree of disability & & & 0.968 \\
\hline Grade 1 & $6(18.8)$ & $2(20.0)$ & \\
\hline Grade 2 & $15(46.9)$ & $5(50.0)$ & \\
\hline Grade 3 & $11(34.4)$ & $3(30.0)$ & \\
\hline Presence of comorbidity & & & 0.277 \\
\hline Have & $11(33.3)$ & $5(50.0)$ & \\
\hline None & $22(66.7)$ & $5(50.0)$ & \\
\hline
\end{tabular}

Values are presented as mean \pm standard deviation or number (\%).

${ }^{*} \mathrm{p}<0.05$. 
differences were observed in general characteristics between the experimental and control groups $(p>0.05)$ except for age, which was significantly lower in the control group $(\mathrm{p}<0.05)$. The comparisons of between-group dependent variables showed significant differences for body fat percentage, pulmonary function (forced vital capacity [FVC], forced expiratory volume in 1 second [FEV1]), and sit-to-stand test $(\mathrm{p}<0.05)$; the other variables showed no significant differences $(\mathrm{p}>0.05)$.

Changes in anthropometric, body composition, blood pressure, blood test findings, and pulmonary function before and after the intervention

Table 3 demonstrates the changes in anthropometric and blood tests, body composition and blood pressure analysis, and pulmonary function measurements before and after the 10-week MIP. In the anthropometric measurements of the experimental group, the BMI increased significantly from $25.37 \pm 5.03$ to $25.81 \pm 5.07 \mathrm{~kg} / \mathrm{m}^{2}$ ( $\mathrm{p}<0.05$ ). Fatfree mass also increased from $48.27 \pm 9.56$ to $49.10 \pm 10.12$ $\mathrm{kg}(\mathrm{p}<0.05)$, while body fat percentage reduced from $28.05 \% \pm 11.22 \%$ to $27.90 \% \pm 11.8 \%$ ( $\mathrm{p}<0.05)$. Blood pressure did not change significantly in the experimental group. However, the systolic blood pressure rose from $90 \pm 11.30$ to $121.95 \pm 7.44 \mathrm{mmHg}$ in the control group $(\mathrm{p}<0.05)$. While the experimental group showed no significant changes in blood test findings, the control group had significantly lower total and HDL cholesterol levels, showing decreases from $190.60 \pm 35.52$ to $172.60 \pm 35.53 \mathrm{mg} / \mathrm{dL}(\mathrm{p}<0.05)$ and from $50.20 \pm 19.20$ to $46.60 \pm 19.23 \mathrm{mg} / \mathrm{dL}$, respectively $(\mathrm{p}<0.05)$.

Table 3. Changes of anthropometric, body composition, blood pressure and blood test, and pulmonary function before and after intervention

\begin{tabular}{|cccccc}
\hline & \multicolumn{2}{c}{ Experimental group $(\mathbf{n}=\mathbf{3 3})$} & & \multicolumn{2}{c}{ Control group (n=10) } \\
\cline { 2 - 3 } \cline { 5 - 6 } & Pre & Post & & Pre & Post \\
\hline Anthropometric test & & & & \\
BMI (kg/m $\mathrm{m}^{2}$ ) & $25.37 \pm 5.03$ & $25.81 \pm 5.07^{*}$ & & $27.28 \pm 5.94$ & $27.59 \pm 5.53$ \\
\hline Waist-hip ratio & $0.88 \pm 0.07$ & $0.88 \pm 0.07$ & & $0.88 \pm 0.10$ & $0.90 \pm 0.09$ \\
Body composition analysis & & & & \\
Body fat mass (kg) & $19.83 \pm 10.27$ & $19.96 \pm 10.49$ & & $26.53 \pm 11.80$ & $26.05 \pm 11.21$ \\
\hline Percent body fat (\%) & $28.05 \pm 11.22$ & $27.90 \pm 11.82^{*}$ & & $36.71 \pm 11.79$ & $36.12 \pm 11.81$ \\
\hline Soft lean mass (kg) & $45.45 \pm 9.04$ & $46.15 \pm 9.52$ & & $40.39 \pm 8.56$ & $41.17 \pm 9.10$ \\
\hline Fat free mass (kg) & $48.27 \pm 9.56$ & $49.10 \pm 10.12^{*}$ & & $42.89 \pm 9.02$ & $44.10 \pm 10.17$ \\
\hline Blood pressure & & & & \\
\hline SBP (mmHg) & $122.47 \pm 16.06$ & $123.69 \pm 14.67$ & & $115.90 \pm 11.30$ & $121.95 \pm 7.44^{*}$ \\
\hline DBP (mmHg) & $78.16 \pm 10.44$ & $78.37 \pm 11.10$ & & $75.95 \pm 11.33$ & $76.00 \pm 8.01$ \\
\hline Pulse (beats/min) & $75.40 \pm 8.86$ & $78.57 \pm 13.31$ & & $76.65 \pm 11.94$ & $78.30 \pm 14.36$ \\
\hline Blood test & & & & \\
\hline Total cholesterol (mg/dL) & $185.85 \pm 32.70$ & $186.36 \pm 38.13$ & & $190.60 \pm 35.52$ & $172.60 \pm 35.53^{*}$ \\
\hline Triglyceride (mg/dL) & $121.48 \pm 65.27$ & $104.52 \pm 69.67$ & & $190.40 \pm 105.85$ & $158.50 \pm 108.09$ \\
\hline HDL (mg/dL) & $57.21 \pm 15.36$ & $57.61 \pm 15.00$ & & $50.20 \pm 19.20$ & $46.60 \pm 19.23^{*}$ \\
\hline LDL (mg/dL) & $110.03 \pm 32.56$ & $110.45 \pm 34.51$ & & $111.80 \pm 30.54$ & $104.70 \pm 31.84$ \\
\hline Pulmonary function & & & & \\
\hline FVC (L) & $2.64 \pm 1.19$ & $2.29 \pm 0.93$ & $1.80 \pm 0.63$ & $1.56 \pm 0.79$ \\
\hline FEV1 (L) & $2.36 \pm 0.99$ & $2.00 \pm 0.82$ & $1.40 \pm 0.70$ & $1.40 \pm 0.85$ \\
\hline
\end{tabular}

Values are presented as mean \pm standard deviation.

BMI, body mass index; SBP, systolic blood pressure; DSP, diastolic blood pressure; HDL, high density lipoprotein; LDL, low density lipoprotein; FVC, forced vital capacity; FEV1, forced expiratory volume in 1 second. ${ }^{*} \mathrm{p}<0.05$. 
Table 4. Changes of physical function and quality of life before and after intervention

\begin{tabular}{lccccc}
\hline & \multicolumn{2}{c}{ Experimental group $(\mathbf{n}=\mathbf{3 3})$} & & \multicolumn{2}{c}{ Control group (n=10) } \\
\cline { 2 - 3 } \cline { 5 - 6 } & Pre & Post & & Pre & Post \\
\hline Physical function & & & & \\
6MWT (number/min) & $105.06 \pm 21.01$ & $100.25 \pm 19.34$ & & $110.70 \pm 24.26$ & $101.30 \pm 9.34$ \\
\hline Right hand grip (kg) & $20.40 \pm 7.57$ & $22.40 \pm 8.54^{*}$ & & $21.61 \pm 11.83$ & $21.70 \pm 11.34$ \\
\hline Left hand grip (kg) & $20.63 \pm 6.83$ & $23.92 \pm 3.28^{*}$ & & $21.60 \pm 11.50$ & $21.63 \pm 11.21$ \\
\hline STST & $13.52 \pm 2.30$ & $16.24 \pm 4.80^{*}$ & & $11.30 \pm 1.82$ & $13.80 \pm 4.23^{*}$ \\
HRQOL & & & & \\
EQ-5D index & $0.89 \pm 0.09$ & $0.91 \pm 0.04$ & & $0.92 \pm 0.03$ & $0.89 \pm 0.06$ \\
\hline
\end{tabular}

Values are presented as mean \pm standard deviation.

6MWT, 6-minute walk test; HRQOL, health-related quality of life; STST, sit-to-stand test.

${ }^{*} \mathrm{p}<0.05$.

Changes in physical function and quality of life before and after the intervention

Changes in physical function and HRQOL are presented in Table 4. No differences were observed between the groups with respect to the six-minute walk test ( $p>0.05)$. In the experimental group, the grip strength of both hands increased significantly, from $20.40 \pm 7.57$ to $22.40 \pm 8.54 \mathrm{~kg}$ in the right hand and from $20.63 \pm 6.83$ to $23.92 \pm 3.28 \mathrm{~kg}$ in the left hand $(\mathrm{p}<0.05)$. No significant difference was observed in the control group ( $p>0.05)$. In the sit-to-stand test, significant increases were observed in both groups $(\mathrm{p}<0.05)$. However, no significant changes were observed in either group in relation to health outcomes measured by the EQ-5D ( $p>0.05)$.

\section{Mean differences between dependent variables of two} groups after the intervention

The between-group differences were analyzed using ANCOVA, as shown in Table 5. HDL cholesterol increased more significantly in the experimental thanthat in the control group (effect size $=0.152, p=0.019$ ). However, the other variables showed no significant differences between groups $(\mathrm{p}>0.05)$.

\section{DISCUSSION}

The current study compared outcomes in participants with ID before and after the intervention to assess the effects of a 10-week MIP and used ANCOVA to identify specific variables showing significant differences between the two groups.

A paired t-test within the groups revealed that body fat percentage was the only significantly changed variable after the intervention in the experimental group. This result is partially consistent with those of previous studies reporting that physical activity results in fat mass changes $[32,33]$ and provides evidence that participation in an MIP can improve the body composition of people with ID.

However, we observed no differences in body fat mass and soft lean mass. According to an earlier study [34], health promotion programs, when implemented during a short time, may not be effective at significantly reducing body fat, including belly fat. Andreacci et al. [34] stressed the importance of the duration of physical activity participation as a variable contributing to improved body composition. In other words, a short duration of physical activity may have a limited influence on fat-related composition and the duration of physical activity needs to be adequate to elicita significant reduction in body fat as a whole.

In terms of changes in physical function, only the experimental group showed significantly increased grip strength, suggesting that the MIP had positive effects on upper extremity function. Both groups demonstrated significantly improved performance in the sit-to-stand test. No change in HRQOL was observed in either group. However, a descriptive statistical analysis revealed an upward trend in the experimental group and a downward trend in the control group.

According to the pre-intervention assessment, the groups were not homogenous with regard to all dependent variables. Therefore, an ANCOVA was performed with confounding variables of sex, age, degree of disabil- 
Table 5. Mean difference between the dependent variables of two groups after intervention

\begin{tabular}{|c|c|c|c|}
\hline & Mean difference between groups ${ }^{\text {a) }}(95 \% \mathrm{CI})$ & p-value & Effect size \\
\hline \multicolumn{4}{|l|}{ Anthropometric test } \\
\hline $\operatorname{BMI}\left(\mathrm{kg} / \mathrm{m}^{2}\right)$ & $1.412(0.216$ to 2.608$)$ & $0.022^{*}$ & 0.145 \\
\hline Waist-hip ratio & $-0.029(-0.078$ to 0.019$)$ & 0.228 & 0.041 \\
\hline \multicolumn{4}{|l|}{ Body composition analysis } \\
\hline Body fat mass (kg) & $0.317(-2.015$ to 2.650$)$ & 0.784 & 0.002 \\
\hline Percent body fat (\%) & $0.049(-3.162$ to 3.261$)$ & 0.975 & $<0.001$ \\
\hline Soft lean mass (kg) & $0.283(-1.744$ to 2.310$)$ & 0.779 & 0.002 \\
\hline Fat free mass (kg) & $0.053(-2.467$ to 2.573$)$ & 0.996 & $<0.001$ \\
\hline \multicolumn{4}{|l|}{ Blood pressure } \\
\hline SBP (mmHg) & $-4.374(-10.374$ to 1.625$)$ & 0.148 & 0.059 \\
\hline DBP (mmHg) & $-1.160(-7.836$ to 5.516$)$ & 0.726 & 0.004 \\
\hline Pulse (beats/min) & $5.753(-3.927$ to 15.433$)$ & 0.236 & 0.040 \\
\hline \multicolumn{4}{|l|}{ Blood test } \\
\hline Total cholesterol (mg/dL) & 24.901 (-11.967 to 61.769$)$ & 0.179 & 0.053 \\
\hline Triglyceride $(\mathrm{mg} / \mathrm{dL})$ & $-26.175(-73.146$ to 20.796$)$ & 0.266 & 0.035 \\
\hline $\mathrm{HDL}(\mathrm{mg} / \mathrm{dL})$ & $12.999(2.305$ to 23.693$)$ & $0.019^{*}$ & 0.152 \\
\hline $\mathrm{LDL}(\mathrm{mg} / \mathrm{dL})$ & $18.588(-13.266$ to 50.422$)$ & 0.244 & 0.040 \\
\hline \multicolumn{4}{|l|}{ Pulmonary function } \\
\hline FVC (L) & $0.978(-0.245$ to 2.202$)$ & 0.113 & 0.072 \\
\hline FEV1 (L) & $0.275(-0.824$ to -1.374$)$ & 0.614 & 0.008 \\
\hline \multicolumn{4}{|l|}{ Physical function } \\
\hline 6MWT (number/min) & $16.122(-12.061$ to 44.305$)$ & 0.253 & 0.039 \\
\hline Right hand grip (kg) & $7.204(-2.513$ to 16.920$)$ & 0.141 & 0.063 \\
\hline Left hand grip (kg) & $-4.875(-11.630$ to 1.879$)$ & 0.152 & 0.060 \\
\hline STST & $3.813(-2.750$ to 10.376$)$ & 0.246 & 0.039 \\
\hline \multicolumn{4}{|l|}{ HRQOL } \\
\hline EQ-5D index & $0.505(-1.048$ to 2.059$)$ & 0.513 & 0.013 \\
\hline
\end{tabular}

BMI, body mass index; SBP, systolic blood pressure; DSP, diastolic blood pressure; HDL, high density lipoprotein; LDL, low density lipoprotein; FVC, forced vital capacity; FEV1, forced expiratory volume in 1 second; 6MWT, 6-minute walk test; STST, sit-to-stand test; HRQOL, health-related quality of life; CI, confidence interval.

${ }^{a)}$ Adjusted mean difference using ANCOVA. Positive values indicate an increase in the experimental group compared to control group.

${ }^{*} \mathrm{p}<0.05$.

ity, and comorbidity after adjusting for baseline values to identify dependent variables showing significant differences between the groups. The test revealed significant differences in BMI and HDL cholesterol between the two groups. Specifically, the BMI rose more significantly in the experimental group. This result can be seen as the compound effects of increased muscle mass and decreased fat-free mass in the experimental group.

In addition, the experimental group showed a 12.999 point (95\% confidence interval, 2.305 to 23.693 ) greater increase in HDL cholesterol than that in the control group. In descriptive statistical analysis, HDL cholesterol showed an upward trend in the experimental group and a downward trend in the control group. According to a previous study, higher HDL cholesterol leads to lower LDL cholesterol [35]. In other words, the MIP was effective in reducing LDL cholesterol because it focused on exercise, obesity management, and behavior modification. The lack of a significant difference in LDL cholesterol was observed between the two groups in the current study may 
be attributable to the rather short intervention period.

Physical health is essential for promoting the social participation of people with disabilities. As discussed above, a MIP can be an important strategy for the management of adult diseases. Future studies should continue to develop new MIPs optimized for adults with ID by combining various components. Given the low self-control in people with ID, MIPs must include nutrition intervention in addition to regular exercise training [17]. By providing people with ID with more opportunities to participate in physical activities, MIPs can help them to improve their social interaction skills. In consideration of the tendencies of people with ID, which include low intellectual functioning, fluctuating mood, and fear of challenges [21], physical activity that can provoke their interest will be a crucial element in the development of MIPs targeted at this population.

The current study had the following limitations. First, the small sample size prevents the findings from being generalized. Second, the two groups were not homogenous in the pre-intervention assessment. To resolve this issue, an ANCOVA was performed to compare variables in the two groups. Third, we did not determine the duration of the effectiveness of the MIP used in this study. Further upscaling ofthe design is needed for future studies.

\section{CONFLICT OF INTEREST}

No potential conflict of interest relevant to this article was reported.

\section{ACKNOWLEDGMENTS}

This research was supported by a grant by the Ministry of Health \& Welfare.

\section{AUTHOR CONTRIBUTION}

Conceptualization: Kim YS, Ho SH. Methodology: Hong BK. Formal analysis: Moon JH, Kim YS. Funding acquisition: Ho SH. Project administration: Ho SH. Writing - original draft: Kim YS. Writing - review and editing: Moon JH, Ho SH. Approval of final manuscript: all authors.

\section{REFERENCES}

1. Centers for Disease Control and Prevention. Disability and obesity [Internet]. Atlanta, GA: for Disease Control and Prevention; 2018 [cited 2020 Jun 15]. Available from: https://www.cdc.gov/ncbddd/disabilityandhealth/obesity.html.

2. Ho SH, Kim YS, Yang JH, Ahn BK, Baek YJ, Eun SD, et al. 2017 Disabled person health care project. Seoul: Ministry of Health \& Welfare, National Rehabilitation Center; 2018.

3. Bruffaerts R, Demyttenaere K, Vilagut G, Martinez M, Bonnewyn A, De Graaf R, et al. The relation between body mass index, mental health, and functional disability: a European population perspective. Can J Psychiatry 2008;53:679-88.

4. Doshi JA, Polsky D, Chang VW. Prevalence and trends in obesity among aged and disabled U.S. Medicare beneficiaries, 1997-2002. Health Aff (Millwood) 2007;26:1111-7.

5. Sturm R, Ringel JS, Andreyeva T. Increasing obesity rates and disability trends. Health Aff (Millwood) 2004;23:199-205.

6. Rimmer JH, Yamaki K, Lowry BM, Wang E, Vogel LC. Obesity and obesity-related secondary conditions in adolescents with intellectual/developmental disabilities. J Intellect Disabil Res 2010;54:787-94.

7. Croce RV. Effects of exercise and diet on body composition and cardiovascular fitness in adults with severe mental retardation. Educ Train Ment Retard 1990;25:176-87.

8. Di Francesco V, Zamboni M, Zoico E, Bortolani A, Maggi S, Bissoli L, et al. Relationships between leisure-time physical activity, obesity and disability in elderly men. Aging Clin Exp Res 2005;17:201-6.

9. Hinckson EA, Dickinson A, Water T, Sands M, Penman L. Physical activity, dietary habits and overall health in overweight and obese children and youth with intellectual disability or autism. Res Dev Disabil 2013;34:1170-8.

10. Fine LJ, Philogene GS, Gramling R, Coups EJ, Sinha S. Prevalence of multiple chronic disease risk factors: 2001 National Health Interview Survey. Am J Prev Med 2004;27(2 Suppl):18-24.

11. Halfon N, Larson K, Slusser W. Associations between obesity and comorbid mental health, developmental, 
and physical health conditions in a nationally representative sample of US children aged 10 to 17 . Acad Pediatr 2013;13:6-13.

12. Lopez RP, Hynes HP. Obesity, physical activity, and the urban environment: public health research needs. Environ Health 2006;5:25.

13. Chow BC, Huang WY, Choi PH, Pan CY. Design and methods of a multi-component physical activity program for adults with intellectual disabilities living in group homes. J Exerc Sci Fit 2016;14:35-40.

14. Klein S, Allison DB, Heymsfield SB, Kelley DE, Leibel RL, Nonas C, et al. Waist circumference and cardiometabolic risk: a consensus statement from shaping America's health: Association for Weight Management and Obesity Prevention; NAASO, the Obesity Society; the American Society for Nutrition; and the American Diabetes Association. Obesity (Silver Spring) 2007;15:1061-7.

15. Wu CL, Lin JD, Hu J, Yen CF, Yen CT, Chou YL, et al. The effectiveness of healthy physical fitness programs on people with intellectual disabilities living in a disability institution: six-month short-term effect. Res Dev Disabil 2010;31:713-7.

16. Jo G, Rossow-Kimball B, Lee Y. Effects of 12-week combined exercise program on self-efficacy, physical activity level, and health related physical fitness of adults with intellectual disability. J Exerc Rehabil 2018;14:175-82.

17. Heller T, McCubbin JA, Drum C, Peterson J. Physical activity and nutrition health promotion interventions: what is working for people with intellectual disabilities? Intellect Dev Disabil 2011;49:26-36.

18. Brown M, Duff H, Karatzias T, Horsburgh D. A review of the literature relating to psychological interventions and people with intellectual disabilities: issues for research, policy, education and clinical practice. J Intellect Disabil 2011;15:31-45.

19. Vereenooghe L, Langdon PE. Psychological therapies for people with intellectual disabilities: a systematic review and meta-analysis. Res Dev Disabil 2013;34:4085-102.

20. Browne G, Bramston P. Stress and the quality of life in the parents of young people with intellectual disabilities. J Psychiatr Ment Health Nurs 1998;5:415-21.

21. Taylor JL, Lindsay WR, Willner P. CBT for people with intellectual disabilities: emerging evidence, cogni- tive ability and IQ effects. Behav Cogn Psychother 2008;36:723-33.

22. Hey SP, Kimmelman J. The questionable use of unequal allocation in confirmatory trials. Neurology 2014;82:77-9.

23. Heller T, Sorensen A. Promoting healthy aging in adults with developmental disabilities. Dev Disabil Res Rev 2013;18:22-30.

24. Dalton M, Cameron AJ, Zimmet PZ, Shaw JE, Jolley D, Dunstan DW, et al. Waist circumference, waisthip ratio and body mass index and their correlation with cardiovascular disease risk factors in Australian adults. J Intern Med 2003;254:555-63.

25. Ballor DL, Keesey RE. A meta-analysis of the factors affecting exercise-induced changes in body mass, fat mass and fat-free mass in males and females. Int J Obes 1991;15:717-26.

26. Jansen DE, Krol B, Groothoff JW, Post D. People with intellectual disability and their health problems: a review of comparative studies. J Intellect Disabil Res 2004;48(Pt 2):93-102.

27. Nair A, Ward J, Lipworth BJ. Comparison of bronchodilator response in patients with asthma and healthy subjects using spirometry and oscillometry. Ann Allergy Asthma Immunol 2011;107:317-22.

28. Gibbons WJ, Fruchter N, Sloan S, Levy RD. Reference values for a multiple repetition 6 -minute walk test in healthy adults older than 20 years. J Cardiopulm Rehabil 2001;21:87-93.

29. Bohannon RW, Peolsson A, Massy-Westropp N, Desrosiers J, Bear-Lehman J. Reference values for adult grip strength measured with a Jamar dynamometer: a descriptive meta-analysis. Physiotherapy 2006;92:115.

30. Bohannon RW. Reference values for the five-repetition sit-to-stand test: a descriptive meta-analysis of data from elders. Percept Mot Skills 2006;103:215-22.

31. Kim MH, Cho YS, Uhm WS, Kim S, Bae SC. Crosscultural adaptation and validation of the Korean version of the EQ-5D in patients with rheumatic diseases. Qual Life Res 2005;14:1401-6.

32. Ordonez FJ, Rosety M, Rosety-Rodriguez M. Influence of 12-week exercise training on fat mass percentage in adolescents with Down syndrome. Med Sci Monit 2006;12:CR416-9.

33. Graham A, Reid G. Physical fitness of adults with an 
intellectual disability: a 13-year follow-up study. Res Q Exerc Sport 2000;71:152-61.

34. Andreacci JL, Dixon CB, Lagomarsine M, Ledezma C, Goss FL, Robertson RJ. Effect of a maximal treadmill test on percent body fat using leg-to-leg bioelectrical impedance analysis in children. J Sports Med Phys
Fitness 2006;46:454-7.

35. Albers JJ, Slee A, Fleg JL, O'Brien KD, Marcovina SM. Relationship of baseline HDL subclasses, small dense LDL and LDL triglyceride to cardiovascular events in the AIM-HIGH clinical trial. Atherosclerosis 2016;251:454-9. 